UNIVERSIDADE ESTADUAL DE FEIRA DE SANTANA

Autorizada pelo Decreto Federal n $^{\circ} 77.496$ de 27/04/76

PRÓ-REITORIA DE PESQUISA E PÓS-GRADUAÇÃo

PPPG COORDENAÇÃO DE INICIAÇÃO CIENTÍFICA

XXIV SEMINÁRIO DE INICIAÇÃO CIENTÍFICA DA UEFS

SEMANA NACIONAL DE CIÊNCIA E TECNOLOGIA - 2020

\title{
CONCENTRAÇÃo DA ÁGUA DE COCO PELO MÉTODO DE ULTRAFILTRAÇÃO POR MEMBRANAS
}

\author{
Monaliza Pinto Cerqueira; Abraão Brito Peixoto ${ }^{2}$ \\ 1. Bolsista PIBIC/CNPq, Graduando em Engenharia de Alimentos, Universidade Estadual de Feira de Santana, e- \\ mail: Monaliza.cerqeng@hotmail.com \\ 2. Orientador, Departamento de Tecnologia, Universidade Estadual de Feira de Santana, e-mail: \\ abraaopeixoto@uefs.br
}

PALAVRAS-CHAVE: Cocus nucifera; fruto, qualidade.

\section{INTRODUÇÃO}

A Instrução Normativa n $^{\circ} 27$, de 22 de julho de 2009, define que a água de coco é composta do endosperma líquido do fruto do coqueiro (Cocus nucifera L.), podendo, para sua industrialização, ser adicionada de açúcares, exclusivamente para correção e padronização do teor de sólidos solúveis do produto.

No Brasil, o coqueiro é explorado basicamente para o uso do fruto. A produção de coco está quase totalmente direcionada para a nutrição humana, tanto em sua forma in natura quanto na de produtos industrializados. Desta, 20\% destinam-se à comercialização de sua água. Parte da produção é vendida informalmente para utilização doméstica em diferentes usos culinários regionais (Hoffmann et al., 2002).

Uma vez que o fruto passou a ser de ampla utilização pela população, o conhecimento dos parâmetros físico-químicos e de qualidade da bebida ganhou relevância, motivo pelo qual se justifica a elaboração do presente estudo. O objetivo do presente trabalho foi analisar, quanto à composição físico-química, a água obtida do fruto do coco verde comercializado no município de Feira de Santana-BA, para caracterizar e comparar com os valores estabelecidos na legislação vigente.

\section{MATERIAL E MÉTODOS OU METODOLOGIA}

Os cocos (Cocos nucifera L.), grau de maturação verde foram obtidos no comércio do município de Feira de Santana, BA, Brasil, cujas águas foram submetidas a análises físico-químicas. Para a correção da concentração de sólidos solúveis ( ${ }^{\circ}$ Brix), foi 
adicionada sacarose na proporção de $0,97 \mathrm{~g}$ para $100 \mathrm{~mL}$ de água de coco até que fosse atingido o valor mínimo de $6,75^{\circ}$ Brix, especificado na Instrução Normativa $n^{\circ} 27$, de 22 de julho de 2009 para água de coco concentrada. A determinação de sólidos solúveis, pH, acidez titulável e açúcares redutores foram realizadas conforme metodologia descrita em IAL - Instituto Adolfo Lutz (2008). Todas as análises foram realizadas em triplicata para confiabilidade dos resultados.

\section{RESULTADOS E/OU DISCUSSÃO}

Para as análises de $\mathrm{pH}$, observou-se que as amostras avaliadas se apresentaram dentro dos padrões estabelecidos pela Instrução Normativa $n^{\circ} 27$, de 22 de julho de 2009, que estabelece pH mínimo de 4,3 para água de coco. O pH das amostras de água de coco variou entre 4,81 (A2) e 4,85 (A1) como apresentado no Gráfico 1.

Segundo Pinheiro et. al. (2005) a variação do pH da água de coco é inconstante ao longo do tempo de desenvolvimento do fruto, aumentando no decorrer da maturação. Portanto, a diferença de $\mathrm{pH}$ observado pode ser devido à diferença de maturação do fruto utilizado na obtenção da água.

Gráfico 1: Valor do potencial hidrogeniônico nas amostras de água de coco.



Os percentuais de acidez das amostras de água de coco estão dispostos no Gráfico 2. Os valores variaram entre 1,10 para a amostra A1 e A3 e 1,15 para a amostra A2. Vale ressaltar que a Normativa ${ }^{\circ} 27$, de 22 de julho de 2009 , retirou a acidez como parâmetro de qualidade da água-de-coco. 
Gráfico 2: Percentual de acidez titulável nas amostras de água de coco.

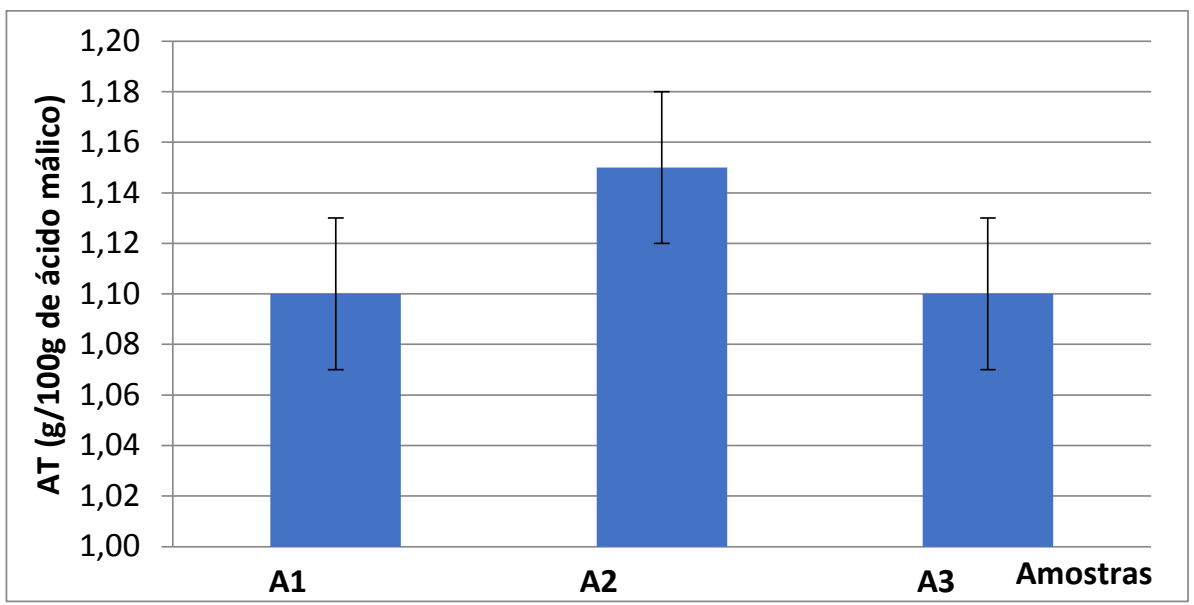

A acidez titulável determina a quantidade de ácido málico (principal ácido orgânico encontrado no fruto) nas amostras de água de coco. A relação entre o pH e acidez estão intimamente relacionadas, pois, à medida em que a acidez diminui, o pH tende a aumentar e isso ocorre devido à maturação do fruto. Essa relação fica bem evidente ao observar os valores encontrados nas análises, no caso da amostra A2, em que apresenta o menor valor de $\mathrm{pH}$ e maior acidez.

A legislação vigente estabelece valor máximo de concentração de sólidos solúveis totais (SST) de $6,70{ }^{\circ}$ Brix para água de coco resfriada e mínimo de $6,75^{\circ}$ Brix para água de coco concentrada. Os teores de sólidos solúveis totais (Gráfico 3) das amostras resfriadas mantiveram-se abaixo do valor estabelecido, variando de 5,23 (A1) a 5,27 (A2). O teor de SST está diretamente relacionado ao dulçor da água do fruto, sendo grande percentagem representada pelos açúcares presentes.

Gráfico 3: Valores de sólidos solúveis totais em ${ }^{\circ}$ Brix nas amostras de água de coco.

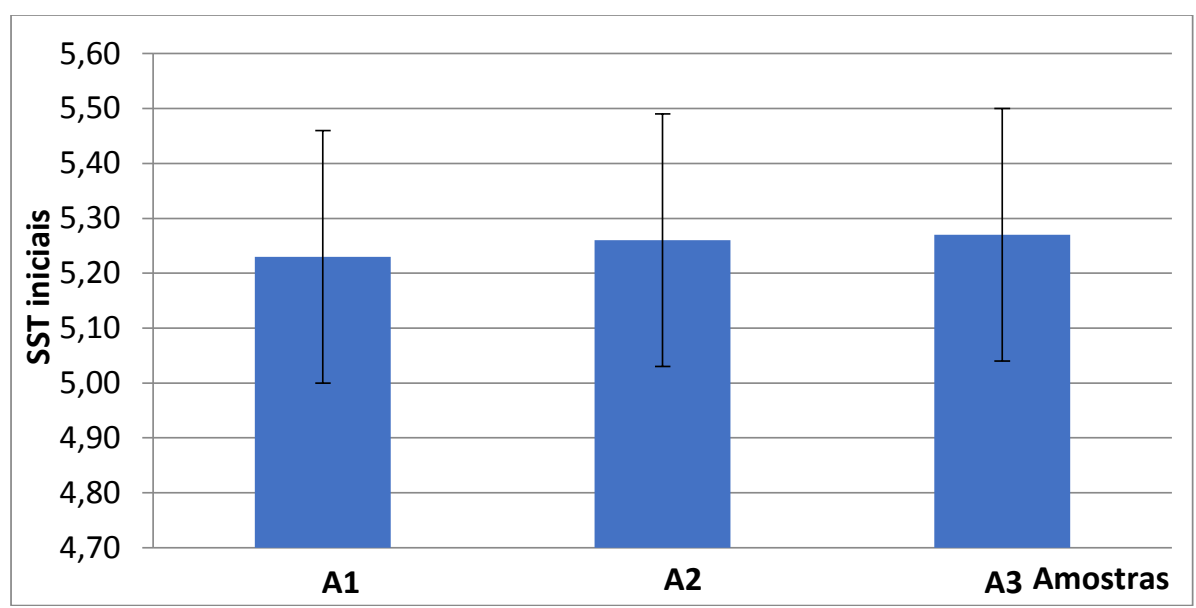


Para as análises de açúcares redutores, observou-se que as amostras avaliadas variaram entre 23,2 para a amostra A1 e 23,6 para a amostra A3. Os valores são apresentados no Gráfico 4.

Gráfico 4: Valores se açúcares redutores nas amostras de água de coco.



\section{CONCLUSÃO}

Os resultados de $\mathrm{pH}$ das amostras da água de coco diferenciam-se em comparação aos valores limites para o fruto in natura apresentados na legislação, enquanto que, os valores iniciais de SST foram bem próximos. Através dos dados obtidos pode-se inferir que a maior diferença foi na análise de açúcares redutores, apresentando o maior valor de desvio padrão $(0,02)$.

É importante ressaltar que, com a maior idade do fruto e maior grau de maturação menor é o valor da acidez titulável e maior o valor do $\mathrm{pH}$, refletindo diretamente na redução da quantidade de açúcares redutores presentes.

\section{REFERÊNCIAS}

HOFFMANN, F. L.; COELHO, A. R.; MANSOR, A. P.; TAKAHASHI, C. M.; VINTURIM, T. M. Qualidade Microbiológica de amostras de água de coco vendidas por ambulantes na cidade de São José do Rio Preto-SP. Higiene Alimentar, v. 16, n. 97, p. 87-92, 2002.

PINHEIRO, A. M.; MACHADO, P. H.; COSTA, J. M. C.; MAIA, G. A.; FERNANDES, A. G.; RODRIGUES; M. C. P.; HERNANDEZ, F. F. H. Caracterização química, físico-química, microbiológica e sensorial de diferentes marcas de água de coco obtidas pelo processo asséptico. Revista Ciência Agronômica, Fortaleza, v. 36, $\mathrm{n}^{\circ}$ 2, p. $209-214,2005$. 